\title{
INTERACTIVE INSTRUCTIONAL: THEORITICAL PERSPECTIVE AND ITS POTENTIAL SUPPORT IN STIMULATING STUDENTS' HIGHER ORDER THINKING SKILLS (HOTS)
}

\author{
Rafika Fauzia Ulfa, Habiddin Habiddin*, Yudhi Utomo \\ Department of Chemistry, Faculty of Mathematics and Natural Sciences, Universitas Negeri Malang \\ Jl. Semarang No. 5 Malang, Indonesia
}

\begin{abstract}
In this disruptive era, the success of teaching approaches that encourage students' creativity and innovation is presented in students' attained high-order thinking skills (HOTS). Consequently, the attainment of HOTS aids someone to avert negative things since they are capable of analyzing and evaluating their obtained information. Besides, HOTS also facilitates the process of students attaining knowledge, generating questions, properly interpreting information, and drawing a conclusion for an issue, with solid reasons, an open mind, and an effective means to communicate it. This article presents a theoretical study on the interactive instructional learning model and identifies its potential in accelerating students' HOTS. It aims to introduce the interactive instructional model in chemistry learning. Further, this model can be adopted in a study with a more intensive evaluation of its empirical contribution to chemistry learning. The learning syntax for this model has been formulated for the Basic Chemistry Class 1.
\end{abstract}

Keywords: Higher Order Thinking Skills (HOTS); interactive instructional; chemistry learning.

\section{INTRODUCTION}

The 4.0 era requires a combination of technological and human skills. Therefore, in the 4.0 era education, high order thinking skills (HOTS) plays a significant role since it facilitates students to solve problems, accurately. It helps students to analyze and evaluate the information they have obtained. Thus, they can evade negative information. Besides, these skills also aid students to gain knowledge, generate questions, interpret information accordingly, and draw a conclusion with robust reasoning, an open mind, and a great way to communicate it.

According to Heong et al., (2016), HOTS is also required in developing someone's ability to generate the ideal decision and solution for a problem. The substantial role of HOTS learning

\footnotetext{
${ }^{*}$ Corresponding author: Department of Chemistry, Faculty of Mathematics and Natural Sciences, Universitas Negeri Malang. Jl. Semarang No. 5 Malang, Indonesia. Email: Habiddin_wuni@um.ac.id
} 
and evaluation has been summarized in a study carried out by Zoller and Dori (2002). In that paper, they accentuate the chemistry learning paradigm shifts from the lower order concern (LOCs) to high order concerns (HOCs) that needed efficient publicity. In our previous studies (Habiddin \& Page, 2020, 2021), we investigate students' HOTS by using pictorial style questions and revealed that students' HOTS were inadequate and at need to be trained regularly and improved in chemistry teaching and learning.

Students' HOTS can be improved using interactive instructional learning. Narciss (2007) explains that interactive learning involves learning strategies that can be classified as interactive and facilitate the learning process. There are three primary components of interactive learning, namely involvement, interaction, and feedback. The examples of stages for interactive instructional learning include sub-topic mapping, question construction, presentation, discussion, and verification. The question proposed during the learning process should be discussed in the groups to associate the concept they have learned and their previous knowledge.

In addition, the factors that may affect students' HOTS are their classroom environment, family characteristic, psychology features, and intelligence (Fearon et al., 2013; Horan, 2007; Lather et al., 2014; Lim \& Smith, 2008; Pannells \& Claxton, 2008). Additionally, the learning model also holds a paramount role to improve students' HOTS. Thus, the interactive instructional model belongs to one of the learning models that develop students' HOTS. As a learning strategy, the interactive instructional model carries some theoretical foundations, such as active learning, cooperative learning, and discovery learning.

\section{OBSERVATION ON EDUCATION QUALITY}

The comparison of Indonesian' and other countries' education quality can be identified from the data presented by Trends International Mathematics and Science Study (TIMSS) and Programme Internationale for Student Assessment (PISA). The data from TIMSS in 2015 show that Indonesia is placed in the $44^{\text {th }}$ position with a score of 397 (IEA, 2016). Meanwhile, the data from PISA (investigation on the reading, science, and mathematic literacy) in 2015, reveal that Indonesia gains the $69^{\text {th }}$ position from the 76 countries, with the science, mathematics, and reading score of 403 , 386, and 397, respectively (OECD, 2016). (Herunata et al., (2020) described that only $12.50 \%$ of the chemistry test items in the State Senior High School 3, 8, and 9 Malang, from the academic year of 2015/2016 to 2017/2018, can be categorized as HOTS questions. The same study also demonstrates that there are only 15\% HOTS items on the test in the academic year of 2015/2016, which increases to $22.5 \%$ in the academic year of $2017 / 2018$. 


\section{INTERACTIVE INSTRUCTIONAL LEARNING SYNTAX}

According to Proske, Körndle and Narciss (2012), interactive learning should facilitate students to interact with the system or other students, during the learning process. That interactive learning supports students to complete the required group of cognitive operation and measures through 1) providing the chance for repetition and correction, 2) instructing them on the learning assignment completion process (such as by explaining the problem-solving process using some sub-assignment that giving the clue for the problems solvency), and 3) giving a reciprocal reaction (such as by providing feedback). Those processes enhance the assignment function, during the learning process. Besides, that interactive assignment also helps students to resolve their incorrect problem-solving stages. It also provides the experiment of authorization and grows the motivation of the students. Consequently, it places the learning material as the primary component of the learning environment.

The three components of involvement, interaction, and feedback should be involved in every interactive learning. The description of those components is presented in Table 1.

Table 1. The Stages of Interactive Instructional Learning (Narciss, 2007).

\begin{tabular}{lll}
\hline No & Learning Stages & Description \\
\hline 1 & Involvement & First, students have to be motivated, internally and \\
& & externally. It aims to engage them with the learning \\
& material so that they can process it. It can be \\
& completed by providing a task or problem to be solved \\
& by the students. \\
\hline 2 & Interaction & Second, students are allowed to interact with the \\
& & learning materials, assignments or problems, so that \\
& & they can comprehend the materials. \\
\hline 3 & Feedback & Third, the decision or action taken by the students \\
& & should be followed by feedback and meaningful \\
& & assessment.
\end{tabular}

INTERACTIVE INSTRUCTIONAL LEARNING'S POTENTIAL IN IMPROVING STUDENTS' HOTS

a) Definition and Characteristics of HOTS

High-order thinking skills (HOTS) represent a higher cognitive process than the process of memorizing and remembering information (Phakiti, 2018). Various literature has provided a different definition of HOTS (Zohar, 2004). However, many studies have identified particular 
criteria to identify HOTS questions. Resnick (1987) described characteristics of the HOTS questions, which include non-algorithmic, more complex than the usual straightforward question, involve various solutions, comprises of judgment and interpretation, requires struggle, while mostly involve uncertainties. Similarly, Zohar and Dori (2003) also explain that the HOTS tasks expect students to develop the argumentation, create a comparison, and complete the demanding nonalgorithmic assignments, resolve controversy and contradictions, as well as investigate the hidden assumption. HOTS instrument is used to measure high-order thinking. It consists of HOTS items that assess the ability to transfer concepts, process information, associate different pieces of information, critically review the information, and use the information to solve a problem.

According to Indonesian Ministry of Education and Culture), the HOTS question should facilitate the students to be able to transfer different concepts, process and implement the information, find the association of various distinctive information, use the obtained information as the source fidea to solve a problem, review an idea and a piece of information, critically. From the aforementioned characteristics, HOTS questions are suggested to be used in school and classroom assessments. In this digital era, students should be educated to sort out information, critically, as well as to respond to that type of information. Therefore, HOTS questions should be formulated using various representations, such as in the form of sentences (verbal), pictures (visual), video, graph, table, symbolic (particular symbol, initial, or sign), and mathematic (formula, number, and equation).

According to the Bloom taxonomy, HOTS questions can be implemented in the understanding, analysis, synthesis, evaluation, and application-level (McLoughlin \& Mynard, 2009). In the revised version of Bloom's taxonomy, HOTS include the implementation, analysis, evaluation, and formulation of question-level (Paideya \& Sookrajh, 2010). Besides, Newman (Lewis \& Smith, 1993) states that HOTS requires students to construe, analyze, and modify information. Currently, the implementation of HOTS has been accentuated in the science, chemistry, and engineering curriculum since it generates a highly qualified learning environment (Toledo \& Dubas, 2016). Therefore, the current education era massively promotes and transforms to adopt HOTS (Ghani et al., 2017). Brookhart (2010) states that HOTS can be reflected in the ability to analyze, evaluate, and create; logic and reasoning; consideration; problem-solving; creativity; and critical thinking. 
Table 2. HOTS Characteristics (Brookhart, 2010)

\begin{tabular}{lll}
\hline & Cognitive Process & Definition \\
\hline C4 & Analyze & $\begin{array}{l}\text { Dividing a material into some parts and decide the } \\
\text { means to associate those parts, their structure, and } \\
\text { their comprehensive purpose. }\end{array}$ \\
\cline { 3 - 4 } & & $\begin{array}{l}\text { Create a consideration, based on particular } \\
\text { standards and criteria. }\end{array}$ \\
\cline { 3 - 4 } & Evaluate & $\begin{array}{l}\text { Arrange elements, simultaneously, to create a } \\
\text { coherent and functioning form or arranging those } \\
\text { elements into a new pattern or form. }\end{array}$ \\
\cline { 2 - 3 } & Create &
\end{tabular}

\section{b) Interactive Instructional Learning's Potential in Stimulating Students' HOTS}

Zoller and Pushkin (2007) state that students with excellent HOTS present great academic achievement, dominate social interaction, and attain emotional maturity. The crucial role of HOTS learning and evaluation in science learning has been presented by Zohar and Dori (2003). Therefore, the chemistry learning paradigm alteration, from LOCs to HOCs should be promoted, properly. Besides, HOTS is also presumed to facilitate the students to grow to be independent and confident learners. The HOTS questions train students to think creatively and critically so that the questions are crucial in improving the future human resource quality (Habiddin \& Page, 2018).

Some factors affect students' HOTS, such as their classroom environment, family nature, psychological characteristic, and intelligence (Fearon et al., 2013; Horan, 2007; Lather et al., 2014; Lim \& Smith, 2008; Pannells \& Claxton, 2008). Students' HOTS can be improved by encouraging them to ask questions, during the learning process. After that, their proposed question can be discussed in the groups. Besides, the process to associate their obtained concepts can also be involved. These learning stages are categorized as an interactive instructional strategy.

Interactive instructional learning relies on the students' discussion. The discussion facilitates the students to learn to develop their ability, social skills, and rational arguments development from their friends and teachers. In interactive instructional learning, students can be grouped, while the interactive strategy can be adopted. Additionally, the teachers should elaborate on the discussion topic, discussion duration, group composition, and the technique of reporting. Besides, interactive instructional learning requires an improvement in the skills of observing, listening, and interpersonal, as well as intervention from the teachers and students. The success of interactive instructional learning highly relies on the teachers' ability to generate and develop the group dynamic. 
Interactive instructional refers to the process of delivering information more directly and authentically. Through interactive learning, students are asked to participate in a group discussion. Interactive learning provides a highly stimulating learning environment and accelerates students' HOTS which becomes the fundamental of analytical reasoning. This learning trains students' decision-making process because students are not merely asked to re-explain the information they have memorized. Besides, interactive learning habituates students to collaborate and work in the group. This skill is crucial since they will work in a structured team, in the future.

In addition, interactive instructional learning also adopts active learning, cooperative learning, and discovery learning.

1. Active learning is a learning approach that involves students discussing, finding a solution for a problem, and adopting a case study or other methods, actively. This approach places a higher responsibility on the students than other passive approaches, such as lecturing. Thus, it is classified as students-centered learning. However, active learning still involves guidance from the teachers. The learning activities in the active learning approach can last for several minutes or some class session. It focuses on the way students learn, as well as on their learning materials. Students are encouraged to think hard or to actively process the information they gathered from the teachers. Through this learning approach, students play an essential role in their learning process. They develop their knowledge and understanding by processing the information provided by the teacher.

2. Discovery learning is a constructivist learning theory applied when students solve a problem using their own experiences and knowledge to find new facts, connections, and truth. Consequently, using this learning approach, students have a greater opportunity to memorize the knowledge and concepts. This learning can be more stimulating and fun for the students. Improvement on some factors induce the discovery and exploration, namely 1) the available theories, 2) students' ability and tendency to develop a theory, and 3) the conducive learning environment.

3. Cooperative represents the cooperation to gain the same goal. In cooperation, an individual looks for meaningful information for themselves and other group members. Therefore, cooperative learning uses the group as the media for students to cooperate and attain maximum learning results. This learning transforms the role of students and teachers within the classroom. The learning becomes student-centered. Thus, students have a bigger chance to actively participate in the learning process, through questioning, sharing, and discussing their ideas. By accelerating academic learning, this learning helps students to create reasonable 
ideas that consider distinctive perspectives, as well as improve their confidence, motivation, and empathy.

4. Peer teaching/collaboration is based on the theory that knowledge is a social construct. This learning is mostly based on four principles. First, students should be the focus of learning activities. Second, students' interactions and activities should be prioritized. Third, the contribution to the group is crucial. Fourth, the structured approach to generate a solution should be adopted. Collaborative learning can be carried out in pairs or a bigger group. This learning obligates the students to work in pairs or small groups to discuss a concept or solution to a problem. It enables students to take the responsibility to review, manage, and consolidate their current knowledge and material, understand the basic concept, fill the emptiness, find the additional knowledge, and re-formulate the knowledge into a new conceptual framework. Learning from their peers increases the learning for all students involved in the learning process.

\section{CONCLUSION}

This study results suggest that interactive instructional learning improves students' HOTS. The interactive learning technique includes the learning strategies that facilitate learning and can be categorized as interactive. Three primary components of interactive learning are involvement, interaction, and feedback. These three components grow students' sense of responsibility, encourage them to comprehend a learning material, and develop their HOTS.

\section{REFERENCES}

Brookhart, S. M. (2010). How To Assess Higher Order thinking Skills in your classroom. Alexandria. Fearon, D. D., Copeland, D., \& Saxon, T. F. (2013). The Relationship Between Parenting Styles and Creativity in a Sample of Jamaican Children. Creativity Research Journal, 25(1), 119-128. https://doi.org/10.1080/10400419.2013.752287

Ghani, I. . B. ., Ibrahim, N. ., Yahaya, N. ., \& Surif, J. (2017). Enhancing students' HOTS in laboratory educational activity by using concept map as an alternative assessment tool. Chemistry Education Research and Practice, 18(4), 849-874. https://doi.org/10.1039/C7RP00120G

Habiddin, H., \& Page, E. M. (2020). Probing Students' Higher Order Thinking Skills Using Pictorial Style Questions. Macedonian Journal of Chemistry and Chemical Engineering, 39(2), 251263. https://doi.org/10.20450/mjcce.2020.2133

Habiddin, H., \& Page, E. M. (2021). Examining Students' Ability to Solve Algorithmic and Pictorial Style Questions in Chemical Kinetics. International Journal of Science and Mathematics Education, 19(1), 65-85. https://doi.org/10.1007/s10763-019-10037-w

Habiddin, H., \& Page, E. M. (2018). Measuring Indonesian chemistry students' Higher Order Thinking Skills (HOTS) in solving chemical kinetics questions. In Y. Rahmawati \& P. C. Taylor (Eds.), Empowering Science and Mathematics for Global Competitiveness; Proceedings of the Science and Mathematics International Conference (SMIC 2018) (pp. 215-222). CRC Press Taylor 
\& Francis.

Heong, Y. M., Sern, L., Kiong, T. T., \& Mohamad, M. (2016). The Role of Higher Order Thinking Skills in Green Skill Development.

Herunata, H., Widarti, H. R., Amalia, R., Sulistina, O., Habiddin, H., \& Rosli, M. S. bin. (2020). An analysis of higher order thinking skill (HOTs) in chemistry national examination for senior high school. AIP Conference Proceedings, 2215(1), 20009. https://doi.org/10.1063/5.0000639

Horan, R. (2007). The Relationship Between Creativity and Intelligence: A Combined YogicScientific Approach. Creativity Research Journal, 19(2-3), 179-202. https://doi.org/10.1080/10400410701397230

Lather, A. S., Jain, S., \& Shukla, A. D. (2014). Student's Creativity in Relation to Locus of Control: a Study of Mysore University, India. The International Journal of Indian Psychólogy, 2(1), 146-165. http://ijip.in/article-details/?dip=18-01-058-20140201

Lewis, A., \& Smith, D. (1993). Defining Higher Order Thinking. Theory Into Practice, 32(3), 131137.

Lim, S., \& Smith, J. (2008). The Structural Relationships of Parenting Style, Creative Personality, and Loneliness. Creativity Research Journal, 20(4), 412-419. https://doi.org/10.1080/10400410802391868

McLoughlin, D., \& Mynard, J. (2009). An analysis of higher order thinking in online discussions. Innovations in Education and Teaching International, 46(2), 147-160.

Narciss, S. (2007). Feedback Strategies for Interactive Learning Tasks. In Handbook of Research on Educational Communications and Technology. Routledge. https://doi.org/10.4324/9780203880869.ch11

Paideya, V., \& Sookrajh, R. (2010). Exploring the use of supplemental instruction: Supporting deep understanding and higher-order thinking in Chemistry. South African Journal of Higher Education, 24(5), 758-770.

Pannells, T. C., \& Claxton, A. F. (2008). Happiness, creative ideation, and locus of control. Creativity Research Journal, 20(1), 67-71. https://doi.org/10.1080/10400410701842029

Phakiti, A. (2018). Assessing Higher-Order Thinking Skills in Language Learning. In The TESOL Encyclopedia of English Language Teaching (pp. 1-7). https://doi.org/doi:10.1002/9781118784235.eelt0380

Proske, A., Körndle, H., \& Narciss, S. (2012). Interactive Learning Tasks BT - Encyclopedia of the Sciences of Learning (N. M. Seel (ed.); pp. 1606-1610). Springer US. https://doi.org/10.1007/978-1-4419-1428-6_1100

Resnick, L. B. (1987). Education and Learning to Think. National Academy Press.

Toledo, S., \& Dubas, J. M. (2016). Encouraging Higher-Order Thinking in General Chemistry by Scaffolding Student Learning Using Marzano's Taxonomy. Journal of Chemical Education, 93(1), 64-69. https://doi.org/10.1021/acs.jchemed.5b00184

Zohar, A. (2004). Elements of Teachers' Pedagogical Knowledge Regarding Instruction of Higher Order Thinking. Journal of Science Teacher Education, 15(4), 293-312. https://doi.org/10.1023/B:JSTE.0000048332.39591.e3

Zohar, A., \& Dori, Y. J. (2003). Higher Order Thinking Skills and Low-Achieving Students: Are They Mutually Exclusive? Journal of the Learning Sciences, 12(3), 145-181. https://doi.org/10.1207/S15327809JLS1202_1

Zoller, U, \& Dori, Y. J. (2002). Algorithmic, LOCS and HOCS (chemistry) exam questions: performance and attitudes of college students. International Journal of Science Education, 24(2), 185-203. https://doi.org/10.1080/09500690110049060

Zoller, Uri, \& Pushkin, D. (2007). Matching Higher-Order Cognitive Skills (HOCS) promotion goals with problem-based laboratory practice in a freshman organic chemistry course. Chemistry Education Research and Practice, 8(2), 153-171. 